\title{
Penerapan Instrumen Three-Tier Test untuk Mengidentifikasi Miskonsepsi Siswa SMA pada Materi Keseimbangan Benda Tegar
}

\author{
Aufa Maulida Fitrianingrum ${ }^{1}$, Sarwi ${ }^{2}$, Budi Astuti $^{3}$ \\ 1,2,3 Jurusan Fisika, Fakultas Matematika dan Ilmu Pengetahuan Alam, \\ Universitas Negeri Semarang, Semarang, Indonesia, 50229
}

\begin{abstract}
Abstrak
Penelitian ini bertujuan untuk mengidentifikasi dan menganalisis miskonsepsi yang terjadi pada siswa tentang keseimbangan benda tegar. Sub-materi keseimbangan benda tegar yang diambil adalah momen inersia, momen gaya, dan titik berat. Metode penelitian yang digunakan adalah metode kualitatif dengan melibatkan 35 siswa SMA. Pengambilan sampel menggunakan teknik purposive sampling. Data penelitian diambil menggunakan instrumen tes diagnostik berbentuk three-tier test. Berdasarkan hasil analisis kualitatif terhadap jawaban siswa disimpulkan bahwa telah terjadi miskonsepsi pada siswa. Miskonsepsi paling banyak terjadi pada konsep momen inersia dan pada aspek kognitif mengingat.
\end{abstract}

Kata Kunci: Tes Tiga Tingkat, Miskonsepsi, Keseimbangan Benda Tegar

\begin{abstract}
The purpose of this research was to identify and analyze the students 'misconceptions of rigid body equilibrium concept. This research was included inertia moment, torque, and centre of gravity concept. This reseacrh used qualitative method. There were 35 students as sample chosen by purposive sampling technique. The research data was obtained by diagnostic test used three-tier test. Based on the qualitative analysis result to the students' answers could be conclude that there were misconceptions. The high misconceptions were happenned in moment inertia concept and cognitive domain "remember".
\end{abstract}

Keywords: Three-Tier Test, Misconceptions, Rigid Body Equilibrium

\section{PENDAHULUAN}

Pemahaman konsep merupakan salah satu faktor penting dalam pembelajaran fisika. Hal ini berarti siswa tidak hanya menghafal materi fisika semata, namun siswa lebih diharapkan agar mampu mengetahui peran dan manfaat fisika sebagai ilmu terapan di kehidupan. Pemahaman konsep adalah kemampuan siswa dalam menerjemahkan, menafsirkan, dan menyimpulkan suatu konsep atau kemampuan menangkap makna arti

Universitas Negeri Semarang

Email: aufamaulidaf8@gmail.com
(C2017 Universitas Islam Negeri Walisongo $\mid 88$ ISSN: 2088-7868, e-ISSN 2502-5708 
suatu konsep (Sanjaya, 2008: 126). Pemahaman konsep merupakan dasar dari Pemahaman prinsip-prinsip teori, artinya agar dapat memahami prinsip dan teori harus dikuasai terlebih dahulu konsep-konsep yang menyusun prinsip tersebut. Pemahaman konsep $m$

erupakan suatu upaya ke arah pemahaman siswa untuk memahami hal-hal lain di luar pengetahuan sebelumnya.

Keberhasilan siswa dalam belajar fisika ditentukan oleh pemahaman siswa terhadap konsep yang diperoleh. Krathwohl (2002: 4) menyatakan bahwa untuk memahami konsep suatu materi, siswa harus memahami enam kategori proses kognitif dalam taksonomi Bloom yaitu mengingat $(\mathrm{C} 1)$, memahami (C2), menerapkan (C3), menganalisis (C4), mengevaluasi (C5), dan membuat (C6). Pemahama n konsep ini akan mempengaruhi siswa dalam menyelesaikan setiap permasalahan yang diberikan oleh guru. Sumber kekeliruan dalam memahami konsep dapat terjadi karena penafsiran diri siswa yang salah atau yang disebut dengan miskonsepsi (Berg, 1991: 4). Miskonsepsi adalah konsep yang tidak sesuai dengan konsep yang berkembang (Kucuk et al., 2005).

Secara umum, langkah-langkah yang dapat digunakan untuk membantu peserta didik mengatasi miskonsepsi adalah mencari bentuk miskonsepsi yang dimiliki, mencari penyebabnya, dan menentukan cara yang sesuai untuk mengatasi miskonsepsi. Miskonsepsi pada siswa dapat diukur dengan berbagai cara yaitu pembuatan peta konsep, tes diagnostik, wawancara, diskusi dalam kelas, dan praktikum melalui tanya jawab (Gurel et al, 2015). Tes diagnostik telah banyak dikembangkan untuk menganalisis miskonsepsi siswa lebih dalam. Tes diagnostik dapat berupa tes berbentuk soal pilihan ganda maupun uraian. Soal pilihan ganda untuk mendeteksi miskonsepsi siswa telah dikembangkan dari one-tier menjadi two-tier dan three-tier. Perbedaan antara two-tier dan one-tier adalah adanya alasan yang harus diberikan siswa setelah memilih jawaban. Instrumen three-tier merupakan pengembangan dari two-tier, di mana pada tes diagnostik tingkat tiga ini siswa memberikan tingkat keyakinannya dalam menjawab. Ukuran tingkat keyakinan/kepastian responden dalam menjawab setiap pertanyaan (soal) yang diberikan, yang dikembangkan untuk dapat membedakan antara siswa yang mengalami miskonsepsi dan tidak tahu konsep disebut certainty of response index (CRI) (Tayubi, 2005: 9).

Beberapa penelitian telah dilakukan untuk mengetahui efektivitas instrumen threetier test seperti untuk mengetahui miskonsepsi tentang rangkaian listrik, konsep gravitasi, 
konsep kalor, dan konsep gelombang (Pesman dan Eryilmaz, 2010; Kaltakci dan Didis, 2007; Eryilmaz, 2010; Caleon dan Subramaniam, 2010). Berdasarkan hasil wawancara dengan beberapa guru fisika SMA Negeri 1 Ungaran, materi keseimbangan benda tegar merupakan salah satu materi yang sulit bagi kebanyakan siswa. Pada materi ini siswa harus memahami konsep benda tegar melalui operasi matematis vektor sekaligus menggunakan gabungan gerak translasi dan rotasi. Ada beberapa materi keseimbangan benda tegar yang masih sulit dipahami oleh siswa yaitu momen inersia, momen gaya, dan titik berat. Pada materi momen inersia, siswa memiliki kesulitan dalam penentuan arah dan besarnya jarak partikel ke posisi sumbu putar. Pada materi momen gaya, siswa masih banyak yang kesulitan dalam menentukan arah perputaran momen gaya. Pada materi titik berat, masih terdapat beberapa siswa yang menganggap bahwa titik berat benda selalu berada di tengah benda. Padahal tidak semua benda memiliki titik berat di tengah benda. Oleh karena itu, peneliti bermaksud untuk mengidentifikasi miskonsepsi siswa dalam memahami konsep keseimbangan benda tegar dengan menggunakan instrumen yang sama. Tujuan dari penelitian ini adalah untuk mengidentifikasi dan menganalisis miskonsepsi yang terjadi konsep siswa tentang keseimbangan benda tegar.

\section{METODE PENELITIAN}

Metode penelitian yang digunakan dalam penelitian ini adalah metode kualitatif. Hal ini karena penelitian ini bertujuan untuk mendeskripsikan dan mengungkapkan miskonsepsi siswa pada materi keseimbangan benda tegar. Sampel dari penelitian ini adalah siswa kelas XI MIPA 4 SMA Negeri 1 Ungaran pada semester genap tahun ajaran 2015/2016. Pengambilan sampel dilakukan dengan menggunakan teknik purposive sampling (Sugiyono, 2009: 85). Penetapan sampel menggunakan pertimbangan dari guru berdasarkan respon belajar, antusiasme, dan partisipasi.

Miskonsepsi siswa pada penelitian ini diuji dengan menggunakan soal diagnostik dengan jenis three-tier test. Three-tier test terdiri dari lima pilihan jawaban, alasan terbuka terhadap jawaban pilihan ganda yang dipilih, serta CRI. Skala CRI yang digunakan pada penelitian ini adalah CRI skala enam $(1-6)$ yang dikembangkan oleh Caleon dan Subramaniam (2010: 955). Skala 1 berarti jawaban total ditebak (totally guessed answer), skala 2 berarti jawab nyaris ditebak (almost guess), skala 3 berarti jawaban tidak yakin (not sure), skala 4 jawaban yakin (sure), skala 5 jawaban hampir 
pasti (almost certain), dan skala 6 keyakinan jawaban pasti benar (certain). Tipe soal yang digunakan adalah menurut taksonomi Bloom yang terdiri dari mengingat (C1), memahami (C2), menerapkan (C3), dan menganalisis (C4).

Penilaian menggunakan sistem biner, di mana setiap jawaban pada pilihan jawaban benar diberi skor 1 dan jawaban salah diberi skor 0. Penilaian untuk alasan terbuka yaitu alasan yang tepat diberi skor 1 dan alasan tidak tepat diberi skor 0. Penilaian untuk taraf keyakinan adalah 1 untuk taraf keyakinan $4-6$ dan 0 untuk taraf keyakinan $1-3$. Teknik analisis menurut Pesman dan Eryilmaz (2010) ditunjukkan pada Tabel 1.

Tabel 1 Teknik Analisis Kombinasi Jawaban

\begin{tabular}{llll}
\hline Kategori & Tipe Jawaban & Skor & Total Skor \\
\hline Memahami konsep & Benar + Benar +Yakin & $1+1+1$ & 1 \\
Kurang memahami konsep & Benar + Benar + Tidak Yakin & $1+1+0$ & 0 \\
& Salah + Benar + Tidak Yakin & $0+1+0$ & 0 \\
& Benar + Salah + Tidak Yakin & $1+0+0$ & 0 \\
& Salah + Salah + Tidak Yakin & $0+0+0$ & 0 \\
Miskonsepsi false positive & Benar + Salah + Yakin & $0+1+1$ & 0 \\
Miskonsepsi false negative & Salah + Benar + Yakin & $1+0+1$ & 0 \\
& Salah + Salah + Yakin & $0+0+1$ & 0 \\
\hline
\end{tabular}

Analisis deskriptif persentase ini digunakan untuk mencari berapa persentase siswa yang memahami konsep, kurang memahami konsep, mengalami miskonsepsi false positive, dan miskonsepsi false negative. Rumus untuk mencari persentase memahami konsep, kurang memahami konsep, miskonsepsi false positive, dan miskonsepsi false negative adalah sebagai berikut.

keterangan:

$$
P=\frac{n}{N} \times 100 \%
$$

$P \quad:$ Persentase siswa pada setiap kategori

$n \quad$ : jumlah siswa pada setiap kategori

$N$ : jumlah seluruh siswa

\section{HASIL DAN PEMBAHASAN}

Nilai yang didapat dari pretest dan posttest dianalisis dan dikelompokkan berdasarkan kriteria pemahaman konsep yang terdiri dari memahami konsep, kurang memahami konsep, miskonsepsi false positive, dan miskonsepsi false negative. Materi keseimbangan benda tegar pada penelitian ini dibagi menjadi tiga sub materi yaitu momen inersia, keseimbangan benda tegar, dan titik berat.

\section{Momen Inersia}

Pemahaman konsep pada materi momen inersia ditujukan pada pemahaman konsep 
siswa terhadap persamaan momen inersia serta penerapannya dalam suatu masalah. Hasil persentase dari jumlah siswa dalam pemahaman konsep materi momen inersia ditunjukkan pada Gambar 1.

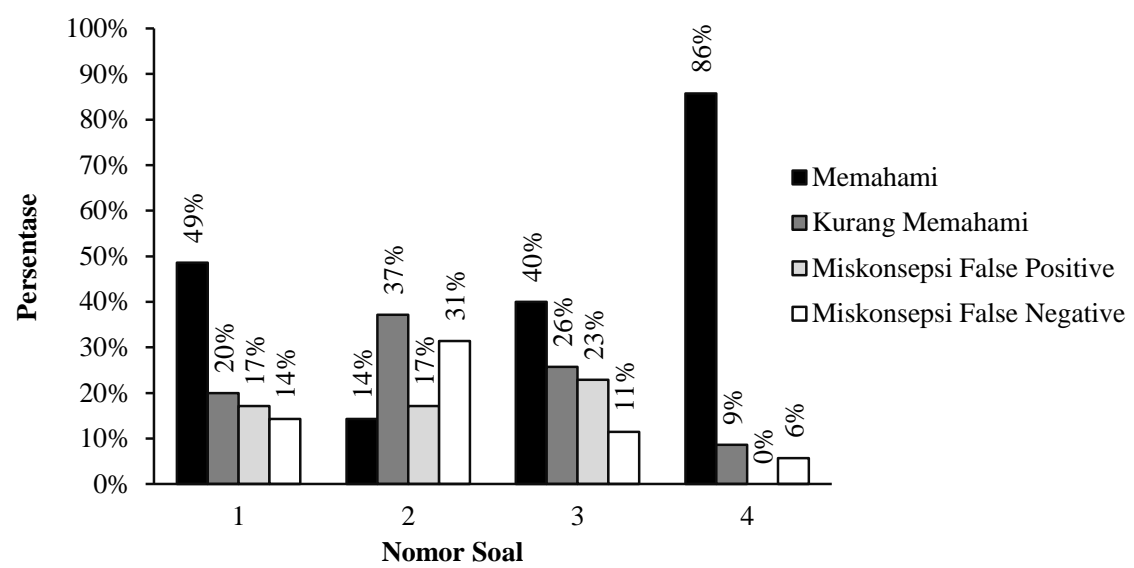

Gambar 1 Grafik Persentase Jumlah Siswa dalam Pemahaman Konsep Momen Inersia

Soal nomor satu merupakan soal dengan ranah kognitif memahami (C2) yang digunakan untuk mengetahui sejauh mana pemahaman siswa terhadap faktor yang mempengaruhi besarnya momen inersia. Pemahaman konsep nomor satu tergolong cukup baik, karena hampir setengah dari jumlah siswa yaitu $49 \%$ menjawab dengan tepat. Presentase siswa yang kurang memahami konsep sebanyak 20\% dikarenakan siswa menjawab soal dengan jawaban yang kurang tepat dan tanpa menuliskan alasan dalam menjawab soal nomor satu ini. Sebanyak $17 \%$ siswa mengalami miskonsepsi false positive dikarenakan memilih jawaban yang benar namun memberikan alasan yang kurang tepat. Siswa yang mengalami miskonsepsi false negative sebesar $14 \%$. Miskonsepsi false negative yang dialami dikarenakan siswa belum memahami secara utuh terkait pengertian besaran $r$, salah satu faktor yang mempengaruhi momen inersia, yang merupakan jarak partikel atau benda ke sumbu putar. Tiga orang siswa menganggap bahwa $r$ merupakan titik pusat, posisi, dan jari-jari sehingga menganggap bahwa hanya massa $(m)$ yang mempengaruhi momen inersia. Adapun siswa yang mengalami miskonsepsi ini menganggap bahwa terdapat empat faktor momen inersia yaitu massa $(m)$, posisi sumbu putar $(r)$, momen gaya $(\tau)$, dan percepatan sudut $(\alpha)$. Memang momen inersia memiliki hubungan dengan momen gaya dan percepatan sudut yaitu $\tau=I \alpha$. Berdasarkan persamaan tersebut dapat diketahui bahwa momen inersia (I) yang mempengaruhi momen gaya $(\tau)$, bukan sebaliknya.

Soal nomor dua termasuk dalam ranah kognitif C1 (mengingat) yang membahas 
persamaan momen inersia untuk berbagai benda seperti bola pejal, bola lapis berongga, lingkaran, batang, dan silinder pejal. Miskonsepsi false positive pada soal ini terjadi karena siswa hanya mampu mengingat beberapa rumusan momen inersia berbagai benda. Kebanyakan dari siswa sudah dapat mengingat besarnya momen inersia pada batang yang diputar di ujung dan bahkan terdapat siswa yang menjelaskan besarnya momen inersia jika diputar di pusat benda. Beberapa siswa memberikan alasan yang belum benar dalam mengungkapkan persamaan momen inersia pada lingkaran.

Soal nomor tiga merupakan soal dengan ranah kognitif menerapkan (C3) yang membahas tentang perbandingan momen inersia jika bola dengan jenis berbeda memiliki massa sama namun jari-jarinya berbeda. Pada soal ini, siswa mengalami miskonsepsi false negative dikarenakan kesalahan perhitungan matematis di mana yang seharusnya momen inersia $(I)$ berbanding lurus dengan kuadrat posisi sumbu putar $\left(r^{2}\right)$, namun terdapat tiga orang siswa yang menjawab tanpa kuadrat. Kesalahan perhitungan matematis dalam menghitung besarnya momen inersia dapat terjadi seperti yang dialami oleh siswa pada penelitian yang dilakukan oleh Syahrul (2015).

Soal nomor empat merupakan soal dengan ranah kognitif menganalisis (C4) yang membahas besarnya momen inersia dalam sistem dengan banyak partikel. Siswa yang memahami konsep dalam menerapkan dan menganalisis persamaan momen inersia dalam suatu konsep tergolong tinggi. Pada soal nomor empat tidak terdapat siswa yang mengalami miskonsepsi false positive. Siswa yang mengalami miskonsepsi false negative sebesar $6 \%$. Satu siswa memilih jawaban yang tidak tepat dan tidak memberikan alasan namun yakin dengan jawabannya. Satu siswa lainnya yang mengalami miskonsepsi false negative sebenarnya sudah mengerjakan dengan cara yang tepat dan alasan yang yakin, namun tidak tepat dalam memilih jawaban.

\section{Momen Gaya}

Pemahaman konsep pada materi momen gaya digunakan untuk mengetahui pemahaman siswa dalam menentukan jenis-jenis keseimbangan dan menganalisis masalah yang memuat konsep torsi. Hasil persentase dari jumlah siswa dalam pemahaman konsep materi momen inersia ditunjukkan pada Gambar 2. 


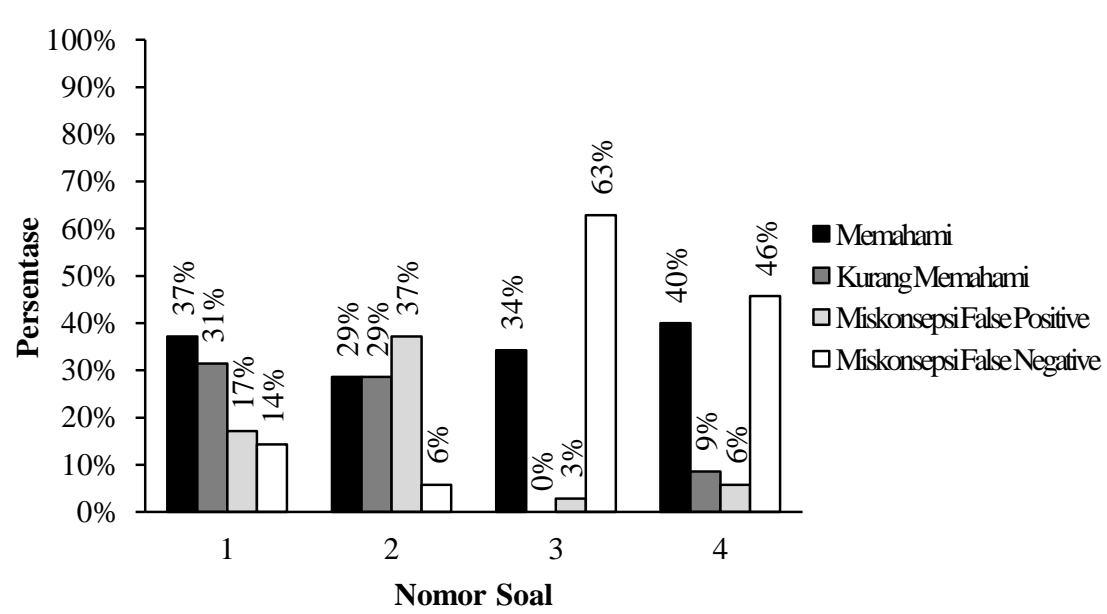

Gambar 2 Persentase Jumlah Siswa Dalam Pemahaman Konsep Momen Gaya

Pada soal nomor lima yang merupakan soal dengan ranah kognitif mengingat (C1), siswa diminta untuk mengingat jenis-jenis keseimbangan dan perbedaannya. Jenis keseimbangan yang dipakai adalah keseimbangan labil yang apabila benda diberi sedikit gangguan maka tidak akan kembali pada keadaan semula. Miskonsepsi yang terjadi pada soal ini adalah siswa belum memahami secara utuh terkait jenis-jenis keseimbangan. Keseimbangan terbagi menjadi tiga jenis yaitu keseimbangan stabil, labil, dan netral. Siswa yang mengalami miskonsepsi false negative masih terdapat yang menjawab dengan jenis keseimbangan translasi dan rotasi. Adapula siswa lainnya tidak memberikan alasan dalam mengerjakan namun menjawab dengan benar dan yakin terhadap jawaban yang diberikan.

Soal nomor enam merupakan soal dengan ranah kognitif memahami (C2) yang membahas tentang penentuan letak titik berat agar diperoleh keseimbangan indeferen (netral). Miskonsepsi pada soal ini terjadi karena siswa menganggap bahwa sebuah benda yang digantung di titik tengah akan mengalami keseimbangan netral. Hal ini berbeda dengan konsep yang menyatakan bahwa keseimbangan benda tegar terjadi pada benda yang apabila diberi gangguan letak titik beratnya tidak berubah.

Soal nomor tujuh merupakan soal dengan ranah kognitif menerapkan (C3). Soal nomor tujuh membahas terkait penerapan rumus momen gaya dalam sebuah konsep. Siswa diminta untuk mencari momen gaya dari beberapa gaya yang terdapat dalam suatu sistem seperti yag ditunjukkan pada Gambar 3. 


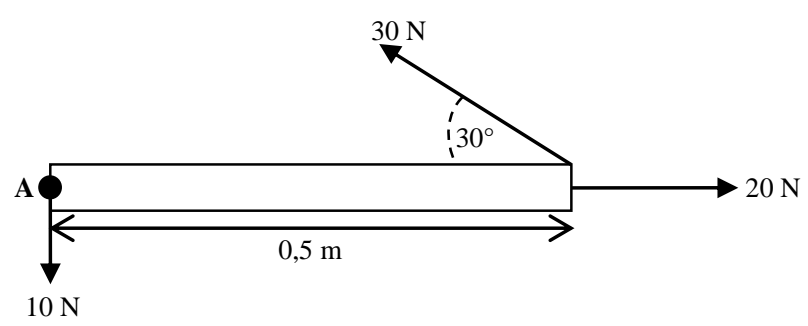

Gambar 3 Ilustrasi Gambar pada Soal Nomor 7

Siswa yang mengalami miskonsepsi false negative sebenarnya sudah memberikan alasan terhadap jawaban yang dipilih. Siswa sudah mengetahui cara mengerjakan soal nomor tujuh adalah dengan menggunakan jumlah total momen gaya yang bekerja pada poros A. Sayangnya, siswa kurang tepat dalam memahami konsep momen gaya di mana gaya yang bekerja harus tegak lurus terhadap lengan gaya. Gambar 3 menunjukkan bahwa gaya yang besarnya $10 \mathrm{~N}$ dan $20 \mathrm{~N}$ akan memiliki nilai momen gaya nol. Hal ini dikarenakan gaya $10 \mathrm{~N}$ tepat berada di poros A sehingga besarnya lengan momen adalah nol. Gaya $20 \mathrm{~N}$ memiliki arah yang sejajar dengan lengan. Karena gaya yang dipakai harus tegak lurus dengan lengan, maka besarnya gaya yang dipakai adalah $F \cos \theta=$ $20 \times \cos 90^{\circ}=0$. Rata-rata siswa yang mengalami miskonsepsi false negative memilih jawaban A $(2.5 \mathrm{~N})$ dan $\mathrm{C}(7.5 \mathrm{~N})$. Miskonsepsi ini terjadi karena siswa menambah atau mengurangkan gaya yang besarnya $20 \mathrm{~N}$ ke dalam total momen gaya.

Soal nomor 8 merupakan ranah kognitif menganalisis $(\mathrm{C} 4)$ yang membahas tentang sebuah sistem menggunakan konsep keseimbangan $\sum F=0$. Miskonsepsi yang terjadi sama dengan miskonsepsi yang terjadi pada soal nomor tujuh yaitu sebenarnya siswa yang mengalami miskonsepsi false negative sudah mengetahui cara menganalisis soal nomor 8 menggunakan konsep keseimbangan $\sum F=0$, tetapi kurang tepat dalam menganalisis gaya-gaya yang bekerja.

\section{Titik Berat}

Pemahaman konsep pada materi momen inersia ditujukan pada pemahaman konsep siswa terhadap definisi pusat gravitasi atau titik berat dan menentukan titik berat pada benda-benda homogen. Hasil persentase dari jumlah siswa dalam pemahaman konsep materi momen inersia ditunjukkan pada Gambar 4. 


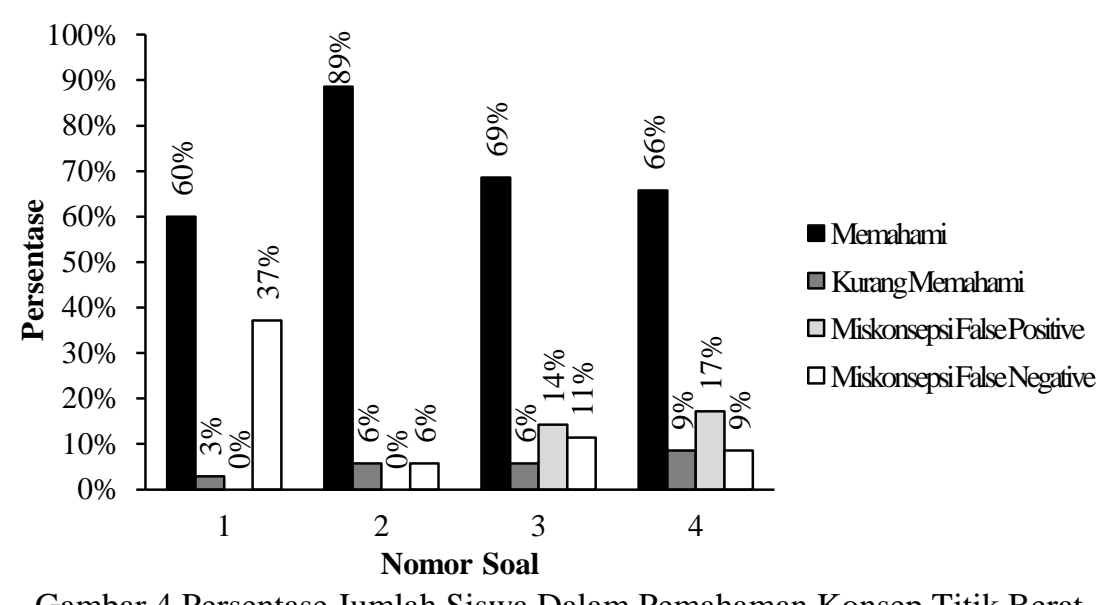

Soal nomor 9 merupakan soal dengan ranah kognitif mengingat (C1) yang membahas tentang pengertian titik berat atau pusat gravitasi. Miskonsepsi yang terjadi adalah miskonsepsi false negative. Hal ini dikarenakan siswa menganggap bahwa titik berat sama dengan pusat massa. Namun sudah terdapat $60 \%$ siswa yang tahu bahwa titik berat sama dengan pusat gravitasi. Hal ini dikarenakan letak titik berat dipengaruhi oleh besarnya percepatan gravitasi yang bekerja pada benda tersebut, sedangkan letak pusat massa tidak dipengaruhi oleh besarnya percepatan gravitasi yang bekerja.

Soal nomor 10 merupakan soal dengan ranah kognitif memahami (C2) di mana siswa diminta untuk memahami perubahan letak titik berat jika benda yang berbentuk diubah menjadi segitiga yang baru seperti yang ditunjukkan pada Gambar 5.

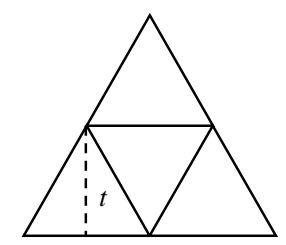

Gambar 5 Ilustrasi Gambar Soal Nomor 10

Miskonsepsi false negative terjadi karena kesalahan matematis yang dialami siswa. Siswa sebenarnya telah memahami bahwa letak titik berat segitiga berada pada $\frac{1}{3} t$, namun siswa tidak menghitung tinggi segitiga yang baru yaitu $2 t$ dan hanya menjawab bahwa letak titik berat segitiga baru berada pada $\frac{1}{3} t$.

Soal nomor 11 merupakan soal dengan ranah kognitif menerapkan (C3) yang membahas terkait penentuan letak titik berat pada sebuah sitem 2 dimensi. Rata-rata siswa yang kurang memahami konsep, mengalami miskonsepsi false positive, dan miskonsepsi 
false negative terjadi karena siswa menebak jawaban. Hal ini karena jawaban letak titik berat pada soal nomor 11 tepat sama dengan titik tengah koordinat benda.

Soal nomor 12 merupakan soal dengan ranah kognitif menganalisis (C4) di mana siswa diminta untuk menentukan titik berat pada benda-benda homogen berbentuk ruang (dimensi tiga). Miskonsepsi pada soal ini terjadi karena kesalahan matematis yang dialami siswa. Siswa sebenarnya telah memahami bahwa untuk mencari letak titik berat benda menggunakan jumlah total letak titik berat dari masing-masing bagian. Siswa telah dapat menuliskan persamaan yang digunakan, namun kurang tepat dalam menjumlahkan.

\section{Tinjauan Setiap Aspek Pemahaman Konsep}

Pemahaman konsep siswa SMA diperlihatkan minimal melalui empat komponen aspek kognitif yaitu mengingat (C1), memahami (C2), menerapkan (C3), dan menganalisis (C4). Hasil pengukuran setiap aspek pemahaman konsep ditunjukkan pada Tabel 2.

Tabel 2 Hasil Pemahaman Konsep Siswa pada Materi Keseimbangan Benda Tegar

\begin{tabular}{lll}
\hline No & Aspek Kognitif & Jumlah siswa (\%) \\
\hline 1 & Mengingat & 37 \\
2 & Memahami & 55 \\
3 & Menerapkan & 63 \\
4 & Menganalisis & 49 \\
\hline
\end{tabular}

Tabel 2 menunjukkan bahwa aspek kognitif yang banyak menimbulkan miskonsepsi adalah aspek mengingat diperlihatkan dengan sedikitnya persentase jumlah siswa yang menjawab dengan benar. Hal ini dapat terjadi karena tingkat berpikir siswa yang berbeda-beda (Halim et al, 2014). Tingkat berpikir siswa dapat mempengaruhi pemahamannya terhadap setiap aspek. Siswa dapat menguasai semua aspek kognitif maupun hanya beberapa aspek saja.

\section{SIMPULAN DAN SARAN}

Simpulan yang dapat diambil dari penelitian ini adalah telah terjadi miskonsepsi pada siswa dalam konsep momen inersia, momen gaya, dan titik berat pada materi keseimbangan benda tegar. Semua konsep yang diteliti menimbulkan miskonsepsi pada siswa. Miskonsepsi pada konsep momen inersia adalah yang paling rendah jika dibandingkan dengan konsep momen gaya dan titik berat.

Aspek kognitif yang paling banyak menimbulkan miskonsepsi adalah aspek kognitif mengingat (C1). Guru diharapkan dapat merancang metode pembelajaran yang 
dapat meningkatkan aspek-aspek kognitif terutama pada aspek mengingat. Guru dapat menggunakan alat bantu seperti video atau aplikasi yang dapat menambah daya ingat siswa. Selain itu, guru juga dapat menghubungkan materi dengan kehidupan sehari-hari yang berhubungan langsung dengan siswa. Remediasi dapat dilakukan agar siswa mengetahui letak miskonsepsi yang dialaminya dan dapat memperbaikinya. Peneliti yang ingin menggunakan metode yang sama dapat mengembangkan instrumen three-tier test pada materi dan mata pelajaran lain.

\section{DAFTAR RUJUKAN}

Caleon, I. dan R. Subramaniam. (2010). Development and Application of a Three-Tier Diagnostic Test to Assess Secondary Students' Understanding of Waves. International Journal of Science Education, 32 (7): 939 - 961.

Eryilmaz, A. (2010). Development and application of three-tier heat and temperature test: Sample of bachelor and graduate students. Eurasian Journal of Educational Research, 40: 53-76.

Gurel, D. K., A. Eryilmaz, dan L. C. McDermott. (2015). A Review and Comparison of Diagnostic Instruments to Identify Students' Misconception in Science. Eurasia Journal of Mathematics, Science, \& Technology Education, 11 (5): 989-1008.

Halim, L., T. K. Yong, dan T. S. M. Meerah. (2014). Overcoming Students' Misconceptions on Force in Equilibrium: An Action Reseacrh Study. Creative Education, 5, 1032-1042.

Kaltakci, D. dan D. Didis. (2007). Identification of pre-service physics teachers' misconceptions on gravity concept: A study with a 3-tier misconception test. Proceedings of the American Institute of Physics, USA, 899: 499-500.

Krathwohl, D. R. (2002). A Revision of Bloom's Taxonomy An Overview. Theory of into Practice, 41 (4): 212-264.

Kucuk, M., S. Cepni, dan M. Gokdere. (2005). Turkish Primary Schools Students' Alternative Conception about Work, Power and Energy. Journal of Physics Teacher Education Online, 3(2): 22-28. Online. Tersedia di http://jpteo.com [diakses 30-09-2016].

Pesman, H. dan A. Eryilmaz. (2010). Development of a Three-Tier Test to Asses Misconception About Simple Electric Circuit. The Journal of Education Research, 103: 208-222.

Sanjaya, W. (2008). Perencanaan dan Desain Sistem Pembelajaran. Jakarta: Kencana.

Sugiyono. (2009). Metode Penelitian Kuantitatif, Kualitatif dan $R \& D$. Bandung: Penerbit Alfabeta.

Syahrul, D. A. dan W. Setyarsih. (2015). Identifikasi Miskonsepsi dan Penyebab Miskonsepsi Siswa dengan Three-Tier Diagnostic Test pada Materi Dinamika Rotasi. Jurnal Inovasi Pendidikan Fisika, 4 (3): 67-70.

Tayubi, Y. R. (2005). Identifikasi Miskonsepsi pada Konsep-Konsep Fisika Menggunakan Certainty of Response Index (CRI). Mimbar Pendidikan No 3/X/XIV/2005. Bandung: Universitas Pendidikan Indonesia.

Berg, V. B. (1991). Miskonsepsi Fisika dan Remediasi. Salatiga: UKSW. 